\title{
Inclusive Education in Higher Education Institutions in Kenya
}

\author{
Dr. Thomas Katua Ngui \\ Senior Lecturer, School of Management and Leadership \\ The Management University of Africa, KENYA
}

\begin{abstract}
The sustainable development Goal 4 on Quality education aims to "Ensure inclusive and equitable quality education and promote lifelong learning opportunities for all." In pursuit of this goal it is necessary for education experts and institutions in Kenya to relook at the issue of inclusive education especially in the Higher education institutions. With the adoption of laws by various Governments to support free and compulsory basic education and the expansion of human rights and anti-discrimination laws in many countries, it is prudent that the children with special needs be supported to access education just like their normal counterparts. The aim of inclusive education is to remove the historical exclusion within and outside of the school through enactment or modification of legislation, policies and educational management practices in order to promote the reorganization of the educational systems and the acceptance of all students irrespective of their differences. The main challenges to inclusive education in Kenya are; lack of policy, attitude, inadequately trained staff, learnerbased challenges and inadequate resources. Governments should invest in overcoming these challenges in order to ensure equal access to education among all learners.
\end{abstract}

Keywords: Special needs education, Inclusive education, Children with disabilities, Higher education, Special education

DOI: $10.7176 / \mathrm{JEP} / 10-3-05$

\section{Introduction}

Over the years the world has been in a constant state of change. This change has affected all sectors of the economy in one way or another. The education sector has not been spared these changes and has had to adjust drastically in order to meet the demands of a rapidly growing population that is increasingly knowledgeable and in need of more skills to solve life's problems. Education is about supporting children to develop in all aspects of their lives - spiritual, moral, cognitive, emotional, imaginative, aesthetic, social and physical (National Council for Special Education, 2014). With the adoption of laws by various Governments to support free and compulsory basic education and the expansion of human rights and anti-discrimination laws in many countries, it is prudent that the children with special needs be supported to access education just like their normal counterparts. Changes in the education sector have demanded a proportionate change in the special education field to accommodate the resulting diversity issues/challenges. It is time for special education leaders and practitioners to reflect and develop a plan that takes into consideration the changing landscape of special education and the impact these changes may have on current and future practices (Gordillo, 2015). This calls for a flexible and responsive learning environment that can adapt to the changing needs of learners (Alberta Education, 2016). Those students with unique challenges need to be supported and nurtured to attain knowledge and skills that will aid them in facing the challenges of the current complex environment. One very great step towards achievement of this broad goal of providing education for all learners irrespective of their disability status is to support inclusive education. This support should extent to all levels of education, including colleges and universities which have historically been ignored to a large extent while supporting the establishment of a suitable learning environment for learners with disability.

\section{Definitions}

Special needs education means the special educational arrangements which are in place for children with disabilities. The free dictionary defines special education as classroom or private instruction involving techniques, exercises and subject matter designed for students whose learning needs cannot be met by a standard school curriculum. The capacity of children with special needs to participate and benefit from education is restricted due to physical, sensory, mental health or learning disability. Those children with special educational needs therefore require additional effort and resources to support their education. Additional resources are those made available over and above the resources generally available to students where no consideration is given to needs of students likely to have particular difficulties in accessing the regular curriculum. These resources include human resources, physical resources, material resources as well as financial resources.

Inclusive education is an approach to education in which all students irrespective of their disability status are placed in the same classroom environment and appropriate support is provided to enable each of them fully achieve the goals of education. According to the Office of the UN High Commission for Human Rights (OHCHR) (2013) inclusive education is a process that recognizes (a) the obligation to eliminate barriers that 
restrict or ban participation and (b) the need to change culture, policy and practice for main stream schools to accommodate the needs of all students, including those (experiencing) disability. In an inclusive school, all students are presumed competent, are welcomed as valued members of all general education classes and extracurricular activities in their local schools, fully participate and learn alongside their same age peers in general education instruction based on the general education curriculum and experience reciprocal social relationships. (TASH, n.d.). Teacher support and an appropriate curriculum are some of the key things in inclusive classes.

\section{Inclusive Education in Higher Education}

Inclusive education is a way of thinking about how teachers can teach and/or design their lessons in different ways so that all children can participate and be involved. Inclusive education means different and diverse students learning side by side in the same classroom (The open society, 2015). Inclusion is a way of thinking and acting that demonstrates universal acceptance of, and belonging for all children and students (Alberta Education, 2016). Inclusive education means encouraging each child to take part in everyday activity of the school and helping every child to achieve the most from school. Inclusive education means ensuring that the system adjusts to meet children's needs, rather than expecting children to 'fit' into the system (National Council for Special Education, 2014).

Inclusive education should consider learner diversity and be flexible enough to meet the needs of each learner. Inclusion is an attitude and approach that embraces diversity and learner differences and promotes equal opportunities for all learners (Alberta Education, 2016). Inclusive education values diversity and the unique contributions each student brings to the classroom (The open society, 2015). Students without disability also benefit when they are in an inclusive class with students with disability. This is because according to McManis (2017) as teachers take into greater consideration their diverse students with disability learners, they provide instruction in a wider range of learning modalities (visual, auditory, and kinesthetic), which benefits their regular education students as well. Teachers in inclusive classrooms should do more to ensure that the children actively participates in the classroom, are learning appropriate material and have opportunities to be involved with other children. The universities and colleges of higher learning in Kenya do not have teachers with knowledge in instructional methods for students with disabilities (Kochung, 2011). This creates a limitation in the achievement of inclusive education in higher institutions.

Different laws globally e.g. The EPSEN Act 2004 require that special needs students should as much as is practically possible be educated in an inclusive environment unless it is practically impossible. Inclusive education strategies should address the barriers faced by learners who are marginalized due to their disability, gender, socio-economic background, religion or ethnic origin among other factors (Global Campaign for Education UK, 2016). According to the EPSEN Act 2004, where the assessment carried under the Act is not in the best interest of both the children with special needs and the other normal children, then the special needs students should be educated in a separate environment. Inclusion requires flexible learning/teachings and assessment based on a flexible and accessible curriculum that is sensitive to individual differences (Kochung, 2011). Successful inclusive education happens primarily through accepting, understanding and attending to student differences and diversity, which can include the physical, cognitive, academic, social, and emotional (McManis, 2017).

According to UNESCO, 1994 Framework for Action on Special Needs Education, inclusive schools must recognize and respond to the diverse needs of their students, accommodating both different styles of learning and ensuring quality education to all through appropriate curricula, organisational arrangements, teaching strategies, resource use and partnerships with their communities (Kochung, 2011).

An inclusive environment ensures all the children have the same right to learn and benefit from the education provided irrespective of their disability status (physical, sensory, mental or learning disability). The education gained should enable all children participate in an inclusive way in the social and economic activities of society and to live independent and fulfilled lives (National Council for Special Education, 2014). Taking an inclusive education approach means forming education strategies that address and remove the barriers that marginalized children e.g. children with disabilities face during the learning process (Global Campaign for Education UK, 2016). Inclusion requires flexible learning/teachings and assessment based on a flexible and accessible curriculum that is sensitive to individual differences (Kochung, 2011). Ensuring that teachers are equipped with child-centred teaching methods, accessible learning materials and school environments provides children with disabilities the opportunity to fully participate in their learning (Global Campaign for Education UK, 2016). Barriers faced by students before enrolling into higher education include; social exclusion and stigmatization by the Society (Kochung, 2011). The development of enabling mechanisms such as national policies on inclusion, local support systems and appropriate forms of curriculum and assessment are important in creating the right context for the development of inclusion (Oyugi, 2011). 


\section{Aims of inclusive education}

When students with disabilities are provided appropriate instruction and supports, they can learn grade-level general education curriculum based on common core state standards, communicate in ways that are commensurate with their same-age peers without disabilities, have meaningful social relationships, and graduate from high school, college and university and are ready for career (Jorgensen, McSheehan, Schuh, \& Sonnenmeier, 2012). According to the National Council for Special Education (2014) the aims of education for pupils with special educational needs are the same as apply to all children. The aim of inclusive education is to remove the historical exclusion within and outside of the school through enactment or modification of legislation, policies and educational management practices in order to promote the reorganization of the educational systems and the acceptance of all students irrespective of their differences.nclusive education recognizes that these differences are valuable and bring creativity and through them ideas are shared and experienced (Kochung, 2011). Therefore, according to the NCSE (2014) education should be about enabling all children, in line with their abilities, to live full and independent lives so that they can contribute to their communities, cooperate with other people and continue to learn throughout their lives. The education of children with disabilities can be made more effective by having high expectations for such children and ensuring their access to the general education curriculum in the regular classroom, to the maximum extent possible (IDEA, 2004). According to the Office of the UN High Commission for Human Rights (OHCHR) (2013) inclusive education is a process that recognizes (a) the obligation to eliminate barriers that restrict or ban participation and (b) the need to change culture, policy and practice for main stream schools to accommodate the needs of all students, including those (experiencing) disability.

\section{Elements of inclusive education}

Inclusion means that the student is truly a member of a class and is valued as much as any other student in that school. Inclusion means that a student will receive the support needed in order to be an active participant, contributor and learner in his or her class, grade and school. The Open Society Foundations (2015) identifies the following three basic elements of inclusive education;

i. Use of teaching assistants or specialists: These staff has the potential to be inclusive or divisive. For instance, a specialist who helps teachers address the needs of all students is working inclusively. The provision of supports for students (i.e., instructional, curricular, behavioral) is viewed as a school-wide need.

ii. Inclusive curriculum: An inclusive curriculum includes locally relevant themes and contributions by marginalized and minority groups. It avoids binary narratives of good and bad, and allows adapting the curriculum to the learning styles of children with special education needs. Supports and special education services are provided in the classroom and coordinated with ongoing instruction.

iii. Parental involvement: According to the Early Childhood Research Institute on Inclusion (ECRII), parents of children without disabilities participating in inclusive programs report positive changes in their children's confidence, self-esteem, and understanding of diversity. Most schools strive for some level of parental involvement, but it is often limited to emails home and occasional parent-teacher conferences. In a diverse school system, inclusion means thinking about multiple ways to reach out to parents on their own terms. The effective implementation of inclusive education systems is the shared responsibility of all educators, leaders and decision-makers. This recognizes and values the diversity of the student body and works with them to enhance and optimize the learning experience for all.

Beliefs and principles of inclusive education

The Best Practices for Inclusion, New Brunswick Department of Education, 1994 identifies the following beliefs and principles of inclusive education:

i. All children can learn. According to Jorgensen, McSheehan, Schuh \& Sonnenmeier, (2012) all students are presumed competent to communicate about and learn general education academic content based on common core state standards when they are provided with high quality, accurate, and consistent support.

ii. All children attend age appropriate regular classrooms in their local schools. This means that the children are placed in classrooms according to their age groups/peers. People use age-appropriate materials, vocabulary, and inflection when talking to students (Jorgensen et al, 2012). This helps all the children to benefit equally from the instructions given.

iii. All children receive appropriate educational programs. Students with disabilities pursue the same learner outcomes as students without disabilities. This ensures that all children have the same benefits from the education.

iv. All children receive a curriculum relevant to their needs. Curriculum and instruction are designed to accommodate the full range of student diversity based on universal design principles. Individualized 
supports are provided to students with significant disabilities to enable them to fully participate and make progress within the general education curriculum (Jorgensen et al, 2012).

v. All children participate in co-curricular and extracurricular activities. Students learn functional or life skills within typical routines in the general education classroom or other inclusive activities and environments (Jorgensen et al, 2012).

vi. All children benefit from cooperation, collaboration among home, among school, among community. Families and schools are engaged in equitable partnership to create quality inclusive educational experiences for students with disabilities (Jorgensen et al, 2012).

\section{Principles of inclusive education}

The Alberta Education, 2016 has identified six principles that are key to achieving an inclusive education system. These principles can guide and inform value-based and learner-centered decisions related to policies, practices and actions at every level of its education system. The six principles are:

i. Anticipate, value and support diversity and learner differences - Welcoming, caring, respectful and safe learning environments create a sense of belonging for all learners and their families.

ii. High expectations for all learners - Creating a culture of high expectations begins with an accessible curriculum and meaningful and relevant learning experiences. Educators and families act on the idea that, with the right instructional supports, every learner can be successful.

iii. Understand learners' strengths and needs - Meaningful data is gathered and shared at all levels of the system - by teachers, families, schools, school authorities and the Ministry - to understand and respond to the strengths and needs of individual learners.

iv. Reduce barriers within learning environments - All education partners' work together to identify and reduce barriers within the curriculum, the learning environment and/or instruction that are interfering with students' ability to be successful learners and to participate in the school community.

v. Capacity building - School leaders, teachers, education professionals, families and community partners have ongoing opportunities, relationships and resources that develop, strengthen and renew their understanding, skills and abilities to create flexible and responsive learning environments. Capacity building takes place at the personal, school and system levels.

vi. Shared responsibility - All education partners, including school and jurisdictional staff, families, community service providers, post-secondary institutions, teacher preparation programs and government are committed to collaboration and are committed to the success of all learners. Inclusive education is possible when all participants, governments, NGOs, teachers, students and communities take action and join their efforts, the goal of achieving equality of access and opportunities for children/youth with visual impairment can start to become a reality (KENPRO, 2010).

\section{The purpose of the principles is to:}

i. Promote equity, access, opportunity and the rights of children and students with disability in education and care.

ii. Contribute to reducing discrimination against children and students with disability where they are treated less fairly than their peers.

iii. Provide early childhood education and care centres (early childhood) and schools with broad and consistent criteria for inclusion so that they assess their progress towards inclusion.

iv. Provide early childhood and school sectors with broad and consistent criteria to assess their progress towards inclusion.

Inclusive practices not only benefit children and students living with disability, they benefit everyone. Inclusive education builds the capacity of early childhood centres and schools to educate and support all students and contributes to stronger school communities.

\section{Gaps in inclusive education in Kenya}

Currently the emphases on special needs education has been at the primary level and to a lesser extend at secondary level. However, the success of such programs remains questionable considering the low number of students with special needs who make it to university level. In most countries in Africa especially south of the Sahara the majority of students with special needs are vulnerable and do not complete high school education and when they complete they do not meet university and college admission criteria that is based on high academic performance and economic ability (Kochung, 2011). Currently very limited or no effort is made at ensuring inclusive education at the tertiary level (universities and colleges). Tertiary education and courses for special education students are limited among our higher education institutions. While an inclusive approach to education 
requires all learners to be taught in the same classroom with support from tutors who have ability to support the special needs students, a greater percentage of university lecturers are not trained as teachers and also very few such lecturers have training on how to deliver education to students with special needs. Besides there is lack of adequately trained academic staff to support special needs education students.

Higher education has been used in many African countries to reinforce inequality in access and success in education as it has remained an agent of exclusion for the vulnerable members of society (Kochung, 2011). While students with special needs are eligible for all degree courses at the University, lecturers with training on special needs education are only available at the departments that train teachers for special education degree programs. Most students with disability are receiving tertiary education in the regular classes under the guidance of lecturers who are not empowered to handle students with special needs therefore they remain excluded. According to Kochung (2011) the barriers to access higher education among people with disability include a narrowly-defined set of legibility criteria, negative attitude, and inaccessible environments. Other barriers that limit a person's full participation include; discriminative policies and practices. Barrier to inclusion have also been attributed to resources. Resource barriers to inclusive education can include; lack of peripatetic services, lack of support staff (sign language interpreters and Braille transcribers), and community involvement, shortage of regular and special teachers among others (Kochung, 2011). According to Oyugi, (2011) teachers' attitudes and values are also factors impeding the progress in implementation of inclusive education in Kenya. As a result of these barriers, students with disabilities are being excluded from accessing higher education in Kenya.

Inclusive education approach is instrumental in addressing these barriers in order to open higher education for students with disabilities and all those who are currently denied access on racial, ethnic, health, linguistic and cultural grounds. It is time for special education leaders and practitioners to reflect and develop a plan that takes into consideration the changing landscape of special education and the impact these changes may have on current and future practices (Gordillo, 2015). Effective education can only take place when students are able to participate fully and benefit from that education (Kochung, 2011). One very important step that governments everywhere need to take is to have a policy of training teachers and lecturers at every level of education on how to handle children with special needs. The curriculum for all training institutions (for teachers and lecturers) should be revised to include some courses that are necessary for them to adequately support and teach students with special needs. The primary, secondary, college and university curriculum should also be modified to include courses that help the students to fully support their peers who have special needs. These courses also help to minimize stigma and exclusion of students with special needs from the social activities of their peers. Unless the governments take such a bold step, then the dreams of an inclusive education approach will remain a mirage.

\section{Challenges to inclusive education}

In Kenya, it is estimated that only one in six disabled children attend school. Those few who are able to attend school face the familiar problems of exclusion, stigmatization, inappropriate curricula, poorly equipped schools and insufficiently trained teachers (Global Campaign for Education UK, 2016). The few vulnerable students especially those with disabilities who complete high school are in special education institutions where the quality of education offered is low due to the negative attitude of teachers (Kochung, 2011). Inclusive education allows the special needs students to easily integrate in the society. This is because they get used to keeping the company of students without disability. Inclusive systems provide a better quality education for all children and are instrumental in changing discriminatory attitudes (The open society, 2015). Respect and understanding grow when students of diverse abilities and backgrounds play, socialize, and learn together. Various challenges that threaten the success of inclusive education in Kenya include:

\section{i. Lack of Policy}

The main challenge to implementation of inclusive education is lack of appropriate policies (Kochung, 2011). Examples of laws that enhance inclusive education include the disability Discrimination Act 1992 , disability Standards for Education, 2005, disability Services Act (SA) 1993, Children's Protection Act, 1993 and South Australian Equal Opportunity Act, 1984 (EOA). Other laws include the Basic Education Act, 2013, Convention against Discrimination in Education, 1960 and the Equality Act 2010 and schools. Universities and colleges of higher learning in Kenya lack policy on inclusive education and are hardly prepared to enroll students with disabilities (Kochung, 2011). Admission criteria to higher education institutions are complex, inflexible and stringent for vulnerable students intending to be enrolled (Kochung, 2011). This lack of policy on higher education means that institutions of higher learning cannot invest in the elimination of barriers, which is evidenced by poor architectural accessibility to higher institution buildings, low number of lectures with training in special needs education and lack of awareness about education for students with disability (Kochung, 2011).

\section{ii. Attitude}

These are perceptions of the people in our environment. In most of the traditional African societies, disabled children are considered suspiciously by the society and in some cases even by their own parents, relatives and 
teachers hence making them feel secluded from the society and even in the family at times. It was believed that disabled people were not fully human or were possessed by evil spirits and brought bad luck because they had been cursed or had a spell placed upon them by witchcraft (KENPRO, 2010). This has led to a lot of stigma that has impaired their ability to attend school and concentrate on their studies. According to KENPRO (2010) disabled people were objects of charity or asylum and subjected to patronizing attitudes based on the nondisabled person's view of them as not fully human or as incapable of living ordinary lives. The society attitudes have either been positive or negative. Negative attitudes have a detrimental effect on the success of inclusive education initiatives. In some cases disabled children have remained locked in their houses to avoid been seen by the community. Teachers' positive attitudes toward inclusion depend strongly on their experiences with learners who are perceived as "challenging" (Oyugi, 2011). Teachers" attitudes towards disabled children can be influenced by teacher education/training, the availability of support within the classroom, class size and overall workload (Oyugi, 2011).

\section{iii. Inadequate Training}

Disabled children in Kenya face the problem of insufficiently trained teachers to handle their needs (Global Campaign for Education UK, 2016). Most teachers in Kenya are not qualified to handle the students with physical challenges (KENPRO, 2010). A research by Williams (2014) found that special education teachers in Kenya struggle delivering the assigned information to children with disabilities in the classroom, due to large class sizes and lack of appropriate special needs education training. Due to the education system emphasizing the ideals of the human capital theory which focuses on the acquisition of the values, attitudes, and skills, the fundamentals to inclusive education are often neglected. Qualified teachers know that classroom needs must be approached from a curricular standpoint in which difficulties are defined depending on each specific task and activity and on classroom conditions (KENPRO, 2010).

iv. Learner based challenges

Ordinary learners and challenged learners have different modes of understanding thus making one ahead of the other (KENPRO, 2010). The challenged students are not fast learners thus need more attention when handling them (KENPRO, 2010). Inclusion can be achievable by adapting the general curriculum and learning outcomes to individual needs, flexible teaching methods and the cooperation between academic faculty members, programme coordinators, student mentors and the students themselves (Björnsdóttir, 2016). Inaccessible environment, lack of support from teachers and school make most of the learners repeat or drop out of school thus not boosting their morale (KENPRO, 2010). While many disabled children do not attend school at all, those who are enrolled in school are far more likely than their nondisabled peers to drop out. This difference can largely be attributed to the fact that disabled children do not receive the amount and type of attention that they need in order to be able to successfully complete their education (Global Campaign for Education UK, 2016).

v. Inadequate resources

While in primary and secondary education, there is additional resource support in terms of personnel, and equipment, there are no support systems in higher education (Kochung, 2011). Resource issues include physical aspects such as inaccessible classrooms to students in a wheel chair, overcrowded classrooms, materials such as Braille and large prints (KENPRO, 2010). Universities need to move from the ivory tower and work with communities so as to provide accessible housing and other services for students with disabilities (Kochung, 2011). Further, teachers have expressed concern about the lack of support from professionals with expertise such as peripatetic teachers or those with expertise in sign language and Braille as well as general special education experts (KENPRO, 2010). Most primary school institutions have sign language teachers and interpreters and brail specialists which higher education institutions do not have. Institutions of higher learning are not prepared to convert text books to electric formats for certain groups of students and provide sign language interpreters and captioning at campus events for those who are deaf or blind (Kochung, 2011). Teachers overwhelmingly believe that inclusive education is impossible without addressing their needs for specialist resources (KENPRO, 2010). The overall belief is that without sufficient resources and support, inclusive education is not possible and is doomed (KENPRO, 2010). Higher education institutions catering for those with disabilities are also not available in every community (Kochung, 2011).

\section{How to advance inclusive education}

To make inclusive education a reality, The Open Society Foundations (2015) recommends that we need to do the following:

i. Ensure that educators have the training, flexibility, and resources to teach students with diverse needs and learning styles. The success of inclusive education in Kenya depends to a very great extent on the availability of well trained special education teachers. Special education teachers in Kenya struggle delivering the assigned information to children with disabilities in the classroom due to lack of appropriate special needs education training (Williams, 2014). Teacher education/training, the availability of support within the classroom, class size and overall workload have an effect on the 
success of inclusive education.

ii. Ensure that kindergartens and schools receive adequate and sustainable financial support so that all activities and services are fully inclusive. Individual African countries have to make commitment to support those who are coming from economically weak background by reducing direct costs on education to individual households and introduce grants and make loans available to those who need it (Kochung, 2011). Student supports are identified and provided to enhance social and academic participation in general education classrooms and other inclusive settings. Culturally responsive and contextually well-fit supports allow for a sense of equity and interdependence.

iii. Empower parents to assert their children's right to education in inclusive settings. Most vulnerable students intending to enroll into higher education are coming from poor economic background (Kochung, 2011). Families are connected to resources for developing their own knowledge base, leadership and advocacy skills (Jorgensen et al, 2012).

iv. Enable the entire community_including mainstream and special educators, social workers, parents, and students - to work together and participate in the design, delivery, and monitoring of education, thereby reframing inclusive education as a shared responsibility. Whenever possible, physical, emotional, and instructional supports are provided by the typical cadre of "experts" within natural environments; classroom teachers, librarians, classmates, office personnel, cafeteria staff, and volunteers. Peer supports are reciprocal. Students have the opportunity to provide support and assistance to others as well as to receive it (Jorgensen et al, 2012).

v. Hold governments accountable for implementing antidiscrimination legislation, legal mandates for inclusion, and policies to remove barriers. As a result of inability to implement human rights policy, there is lack of interest in developing policy on higher education for persons with disability (Kochung, 2011). Lack of interest in developing policy on education of persons with disability may be attributed to poor attitude, ignorance, professional protectionism towards segregated education, antagonism towards inclusive education from within disability itself (Kochung, 2011).

\section{Benefits of inclusive education}

Inclusive education happens when children with and without disabilities participate and learn together in the same classes. Inclusion has important benefits for all children as it produces schools with more enriching learning environments where diversity is viewed as a positive force which must be celebrated (Oyugi, 2011). Inclusive education is a process of removing barriers and enabling all students, including previously excluded groups, to learn and participate effectively within general school systems (KENPRO, 2010).

Many studies have reported positive outcomes among both students with disability and those without disability when inclusive education was practiced. A research conducted by Kalambouka, Farrell, Dyson, and Kaplan (2007), found that including students with disabilities resulted in either positive or neutral effects for students without disabilities. Students have the opportunity to provide support and assistance to others as well as to receive it (Jorgensen et al, 2012). Positive effects of inclusion on students without disabilities include improved attitudes towards diversity (Finke, McNaughton, \& Drager, 2009). Another study by Theoharis and Causton-Theoharis (2010) found improved educational outcomes for students with and without disabilities when inclusion was the primary school reform. According to the New Brunswick Association for Community Living (2000) inclusive education (when practiced well) is very important because:

- All children are able to be part of their community and develop a sense of belonging and become better prepared for life in the community as children and adults.

- It provides better opportunities for learning. Children with varying abilities are often better motivated when they learn in classes surrounded by other children.

- The expectations of all the children are higher. Successful inclusion attempts to develop an individual's strengths and gifts.

- It allows children to work on individual goals while being with other students their own age.

- It encourages the involvement of parents in the education of their children and the activities of their local schools.

- It fosters a culture of respect and belonging. It also provides the opportunity to learn about and accept individual differences.

- It provides all children with opportunities to develop friendships with one another. Friendships provide role models and opportunities for growth.

\section{References}

Alberta Education, (2016). Principles of Inclusive Education.

American Heritage (2016). Dictionary of the English Language, Fifth Edition. Houghton Mifflin Harcourt 
Publishing Company. Published by Houghton Mifflin Harcourt Publishing Company.

Björnsdóttir, K. (2016). Belonging to higher education: inclusive education for students with intellectual disabilities. European Journal of Special Needs Education. Volume 32. Pages 125-136

Finke, E.H., McNaughton, D.B., \& Drager, K.D. (2009). 'All children can and should have the opportunity to learn": General education teachers' perspectives on including children with autism spectrum disorder who require AAC. Augmentative and Alternative Communication, 25(2), 110-122.

Global Campaign For Education UK (2016). Accessing Inclusive Education For Children With Disabilities In Kenya

Gordillo, J.W. (2015) Top 10 Trends in special education in 2015. Scientific learning

Government of South Australia (2017). Principles of Inclusion for Children and Students with Disability in Education and Care. Ministerial Advisory Committee: Children and Students with Disability.

Individuals with Disabilities Education Improvement Act, (2004). PL108-446, 20 U.S.C. 1400 et seq.

Jansen, D.; Petry, K.; Ceulemans, E.; Oord, S.; Noens, I. \& Baeyens, D. (2016). Functioning and participation problems of students with ADHD in higher education: which reasonable accommodations are effective? European Journal of Special Needs Education. Volume 32, 2017 - Issue 1: Pages 35-53

Jorgensen, C.M., McSheehan, M., Schuh, M. \& Sonnenmeier, R.M. (2012). Quality Indicators Of Inclusive Education. National Center on Inclusive Education Institute on Disability/UCEDD University of New Hampshire Durham, NH 03824. http://www.iod.unh.edu

Kalambouka, A., Farrell, P., Dyson, A., \& Kaplan, I. (2007). The impact of placing pupils with special educational needs in mainstream schools on the achievement of their peers. Educational Research, 49(4), 365-382.

KENPRO (2010). Challenges Facing Inclusive Education in Regular Primary Schools in Kenya. KENPRO Online Papers Portal. Available online at www.kenpro.org/papers.

Kochung, E.K. (2011). Role of Higher Education in Promoting Inclusive Education: Kenyan Perspective. Journal of Emerging Trends in Educational Research and Policy Studies (JETERAPS) 2(2):81-87 (ISSN: 2141-6990).

McManis, L.D. (2017). Inclusive Education: What It Means, Proven Strategies, and a Case Study; A Blog By Concordia University- Portland

National Council for Special Education (2014). Children with Special Educational Needs Information Booklet for Parents

New Brunswick Association for Community Living (2000). Achieving Inclusion: A Parent Guide to Inclusive Education in New Brunswick.

OECD, CERI, (2005). Students with Disabilities, Learning Difficulties and Disadvantages: Statistics and Indicators, OECD, Paris

OHCHR (2013). Thematic Study On The Right Of Persons With Disabilities To Education UN Doc $\mathrm{A} / \mathrm{HRC} / 25 / 29$.

Oyugi, L.N. (2011). Inclusive Education in Kenya: Perspectives of Special Educators: Attitudes and Values How can they affect Inclusion? LAP LAMBERT Academic Publishing

TASH (n.d.). Inclusive education. Retrieved from http://tash.org/advocacy-issues/inclusive- education/.

The open society (2015). The Value of Inclusive Education

Theoharis, G., \& Causton-Theoharis, J. (2010) Include, belong, learn. Educational Leadership, 68(2). Retrieved from http://www.ascd.org/publications/educational- leadership/oct10/vol68/num02/Include,-Belong,Learn.aspx

Williams, K. (2014). Education Perspectives: Is Kenya Achieving Inclusive Education? Center For Education Innovations

\footnotetext{
About the author

Dr. Thomas Katua Ngui was born in Machakos County, Kenya in 1977. He holds a Ph.D in Human Resource Management from Jomo Kenyatta University of Agriculture and Technology, Kenya. In addition he holds a Master of Business Administration and a Bachelor of Education degree both from Kenyatta University, Kenya. Dr. Ngui is a career teacher who has risen through the ranks to the position of Senior Lecturer at the University. He has been teaching for the last 19 years. Currently he is a Senior Lecture at The Management University of Africa, Kenya. He has previously served as Deputy Head of Department, Head of Department and Director Graduate Business School at The Catholic University of Eastern Africa, Kenya. Dr. Ngui has taught and Supervised over 100 Post Graduate students in their Research. He is also an External Examiner and teaches at Machakos University, South Eastern Kenya University, Jomo Kenyatta University of Agriculture and Technology, Kenya Institute of Management and Tangaza University College. He is also a consultant at the Kenya Institute of Management. He has published widely in the areas of Human Resources Management, Entrepreneurship, Education and Corporate Governance. Dr. Ngui is also a Director and Chairman of Finance
} 
and General Purpose Committee at Machakos Water and Sewerage Company Limited. Dr. Ngui is a Full Member of the Institute of Human Resources Management, Kenya (IHRM, K) and the Kenya Institute of Management (KIM). 